\title{
Research on the Influence of Big Data on IM in Colleges and Universities
}

\author{
Xiaoyun Fan ${ }^{1, ~ a, ~ J i a n f e n g ~} \mathrm{Lu}^{2, b}$ \\ ${ }^{1}$ Computer Department, Liaoning Petro-chemical Vocational \& Technology College, Jinzhou, 121001, China \\ ${ }^{2}$ College of Finance and Trade, Bohai University, Jinzhou, 121013, China \\ a30270688@qq.com, blujianfeng9999@126.com
}

Keywords: big data; higher education management; informatization management system

\begin{abstract}
In the environment of information education, the educational management mechanism of university has new characteristics and new development direction. In order to explore the essence of educational management information. The management informatization of education in institutions of higher learning should also be characterized by openness, interaction and cooperation. Therefore, this paper puts forward the idea of education management information reform in colleges and universities, and puts forward the new idea of constructing the teaching mode based on information management: strengthen the education management informatization standard system construction, promote the effective integration of education management information system, improve information literacy of the whole education managers, and promote the construction of education management information and on this basis, the establishment of the new teaching model.
\end{abstract}

\section{The Big Data Era Has Carried on the Innovation to the College Education Pattern.}

Although most college courses in traditional colleges and universities are open and open to non-professional students, this mode is still concentrated in teaching resources. College education resources can only be concentrated in universities, but other universities and society cannot spread. But in the era of big data, this kind of centralized teaching mode will be fundamentally changed. Teachers can upload their courses to the network through the Internet, so that students in the network can, on the one hand, listen to the students to deepen their impressions and grasp the key points again and again; on the other hand, Network teaching faces a wider audience, students and social personnel in universities or other universities, so education is no longer limited to universities.

\section{The Problem of Innovation of Management Informatization of Education in Colleges and Universities under Big Data Environment.}

While the information revolution brings benefits to people's lives, it cannot be denied that it will cause some negative effects and cannot be eradicated. All problems with information cannot be expected to be solved, nor can information be treated as a monster. The profound influence of technology on education management and the negative influence of education on technology are all questions we should think deeply about. Education management information is lack of evidence.

In the era of big data, information technology has brought huge amounts of information, making many people no longer eager to investigate. Some managers ignore the actual investigation and download the rules and regulations of other organizations directly from the Internet for the sake of convenience. It is very common in the implementation of the rules and regulations of educational administration. Under the condition that limited information technology knowledge only supplies "when", "where" and "what" is "hard information", if we only consider our results, it is not enough to bring us thought and deal with the problem. If information technology can't match reality, it can only be a blunt and inert application. So, under the support of modern information technology, the combination of information and practice is a problem that must be paid special attention to in the management of education. 
Information security and secrecy are important issues in educational management information. Teachers, students, courses, school books, and teaching Materials, teaching websites and other information constitute educational management information. With the support of modern information technology, especially the information system in education management, because of its openness and interaction, under the complicated procedure, the weakness and omission of the information and education management system make the information possible to be taken out at will. Replication and interception are very common in the process of storage and transmission, resulting in information disclosure and security risks. Although access is established with certain permissions, some confidential information will be stolen or tampered with (e. G. Hackers. As with other computer programs, computer viruses attack educational management systems is extremely harmful, if the system is paralyzed, school-wide teaching will be difficult to wake up, and the resulting damage will be huge. The fragmentation and asymmetry of educational management information. Progress in the information age has given mankind too much information, but it is also a hindrance compared to too little information. The theory of asymmetric information provides an innovative perspective that can be used in the field of education.

In the context of the information age, in colleges and universities, the school as a whole in the students, teachers, teachers and teachers in the interaction between the inherent relationships, there is also a phenomenon of information asymmetry. Especially based on the information asymmetry in the phenomenon of educational management. In teaching and management, the requirements of information technology are different between students and teachers. For example, the level of different requirements for computer operation skills can only be found in the educational management department of the school that publishes information on the website. Ignoring the object itself, it is difficult to ensure the fairness of education. For the evaluation of teachers' teaching quality, teachers may be too strict when collecting students' online feedback, so students will have a variety of factors when they go to evaluate. If the teacher's teaching quality is determined only by the student's unilateral evaluation, it may not promote good teachers and may lead to some irresponsibility More scattered teachers, so that the teaching quality evaluation will not have a certain utility. The overall quality of educational managers is likely to decline.

Monopoly because of the limitation of information technology, information sources and application form, causing the systematization of information standardization program, not only can cause direct and one-sided, also let people effortlessly to linear response, make rigid behavior Make behavior stiff and rigid. Managers who rely heavily on information technology will lose their ability to explore problems independently and become divorced from reality. The above behavior will have a negative impact on the development of the comprehensive quality of education managers.

\section{Factors Causing Problems in Management Informatization of Education in Colleges and Universities}

Not enough comprehensive understanding education management information for teaching the importance of information management, knowledge level between different colleges and universities, planning and decision-making mechanism is not comprehensive, to relevant personnel arrangement is not reasonable, and there is no corresponding information and science team, backward ideas, in the complicated and chaos, there are still a lot of work, now cannot make full use of information technology, complete set of scientific management mechanism has not developed so far.

Saying, the computer can replace the role of the office, the computer is connected to the network, the modern education management informatization, some managers are all afraid of the enthusiasm of the employees for the development of information technology to deepen and desalination. Leadership and coordination to implement, now, in the capital construction of China's colleges and universities information, because few have effective guidance and the harmonic, the administrative department of education at the macro level, promote the construction of information resources is not enough; Lack of uniform standards in development leads to duplication of construction, and compatibility in universities; Rare conciliatory, coordination and mutual aid, in the construction of 
the information capital rare spread of human and other reasons cause the information resources of the redevelopment of the information resources construction seriously lagging behind the actual situation of the minimal set of policy support and the cooperation mechanism, benefit from the education management information in an open, open the sharing of information resources and benefit from the colleges and universities. Under the contemporary policy of colleges and universities, have their own interests for its relatively closed operation system, the redistribution of resources sharing teachers individual rights and interests, the innovation of the support and the method of harmonic, it is urgent to solve the problem Furthermore, the requirements of teachers' comprehensive quality, to adapt to the ability of the information age today, should have in the evaluation of their teaching performance, at the same time, rewards and punishments and incentives should also be innovation and improvement. So, the creation of the scientific educational administration management system is necessary for the teachers' troop.

The construction of teaching staff cannot keep pace with the construction of information technology. One is the influence of traditional educational concepts on Teachers' deep-rooted influence. Second, under the background of new era, to the teacher's ability to have more requirements, whether the knowledge structure, or wait for the specific knowledge, management knowledge and technological knowledge as well as the thinking and excellent ability of the integration of books content and network information, at the same time in the teaching activities of the organization of conscious use of information technology is a must, however, in China's colleges and universities the teaching staff, the quality and ability are relatively weak, so under the background of scientific and informationized education management work is not easy to be used for education management informatization limited education management information system is a complex whole, composed of a series of hardware and software Money at the beginning must be sufficient to support, so as to ensure smoothly, however, today on the funding problems, have difficulty in colleges and universities in our country, it is difficult to ensure there is enough money, so limits the education informatization construction in progress.

\section{The Management Information Path of Education in Colleges and Universities under Big Data Environment}

Reforming and perfecting the Educational Management in Colleges and Universities. Introduction of advanced management ideas only under the guidance of advanced management ideas, education management can develop. In the information age, in addition to the ability of education management, university education administrators should also have advanced management ideas: First, the idea of active adaptation. Second, people-oriented concept. Third, total quality management.

In order to reform the management of teaching plans by means of informatization, the first step is to reform teaching plans. Only good teaching plan can guarantee good teaching quality. Making a good teaching plan is the basis of establishing teaching system, arranging teaching tasks and organizing teaching process. Teaching plans are generally made independently by education scientists or relevant personnel under the guidance of the corresponding departments of education in the country, taking into account the overall benefits. Teaching plans meet the teaching rule, stable over a period of time, but in the long run, also want to continuously adjust and correct, can adapt to the new development of society, economy and the progress of science and technology. The information age requires us to keep up with the trend of The Times, accurately predict the changes of the society's requirements for talents, and cultivate talents that meet the requirements of the state. To achieve this goal, we should make full use of information technology, make the teaching plan, and the real-time monitoring and timely feedback, work out plans for teaching standard of parity, and make the college graduates to meet the requirements of society.

Making teaching plans in big data environment. First, the teaching school program should meet the following requirements: (1) Objectivity. (2) Flexibility. Second, make the general procedure of teaching plan. It is necessary to reform the education mode and management mode of talents. Strengthening the reform of curriculum management cannot emphasize too much on curriculum 
construction. In a sense, the curriculum is more important than the major because it embodies the major. We're going to make a big dinner for our students, not just a good menu, but at least a good meal.

The scientific and standardization of teaching evaluation system for the establishment of teaching evaluation is of vital importance in education evaluation, teaching evaluation is according to the specific teaching goal in a certain teaching system to collect information, accurate understanding, finally, scientific and comprehensive analysis, so that the evaluation can objectively, and can promote the quality of teaching have a rely on, also provide some evidences for the reform. The teaching significance of teaching evaluation is very important. It can be used for guidance, decision making.

\section{Conclusion}

Application of modern information technology in management of education in universities. University education management informatization, high-tech means of automated method, carries on the education management, close to the requirement of times development, is to use computer and multimedia technology in practice today. Nowadays, education management relies more on information network and online decision-making, which is a kind of support and progress. Nowadays, computer information system has been systematically used, which is more of a tool, which plays an important role in information utilization and decision support. In the era of information management, under the influence of developed information, there are higher requirements on people's ability, and high comprehensive quality requirements have changed the personnel structure. Therefore, it is quite urgent to realize innovation to meet the requirements of the information age and make education management a higher level.

\section{Acknowledgement}

This work is supported by research project on teaching reform of Bohai University: Research on efficiency optimization of extracurricular classroom teaching under rotating classroom mode_-Taking the major of the secondary vocational undergraduate marketing as an example (BDJG2016YB05).

This work is supported by scientific research projects of Liaoning Petro-chemical Vocational \& Technology College: Research on network learning analysis method based on big data (LSHYY1704).

\section{References}

[1] Grover V, Jeong S R, Kettinger W J, et al. The Chief Information Officer: A Study of Managerial Roles [J]. Journal of Management Information Systems, 1993, 10(2):107-130.

[2] Peppard, Joe. Unlocking the Performance of the Chief Information Officer (CIO) [J]. California Management Review, 2010, 52(4):73-99.

[3] Penrod J I, Others A. The Chief Information Officer in Higher Education. Professional Paper Series [J]. Attitudes, 1990:51.

[4] Donovan J J. Beyond chief information officer to network manager [J]. Harvard Business Review, 1988, 66(5):134-140.

[5] Gottschalk P. The Chief Information Officer: A Study of Managerial Roles in Norway[C]// 2014 47th Hawaii International Conference on System Sciences. IEEE Computer Society, 2002:241.

[6] Gottschalk P. The Chief Information Officer: A Study of Managerial Roles in Norway (PDF) [M]. DBLP, 2002. 